\title{
Special Issue on "Application of Mechanics of Unsaturated Soils in Conventional Geotechnical Practice"
}

\author{
Sai K. Vanapalli ${ }^{1}$ Laureano R. Hoyos ${ }^{2}$
}

Published online: 24 August 2016

(C) Indian Geotechnical Society 2016

Several advancements have been reported in the literature for better understanding the behavior of unsaturated soils during the last five decades. In spite of the significant developments in theoretical and experimental studies along with numerical investigations during this period, the application of the mechanics of unsaturated soils in the conventional engineering practice has been receiving increasing attention, only recently. The key objective of this Special Issue has been focussed to encourage scholars, researchers, and practitioners to disseminate their most recent studies and experiences on various topics of unsaturated soils.

This Special Issue has attracted papers from well-known researchers from various regions of the world. All the received papers have been peer-reviewed following Indian Geotechnical Journal guidelines. The Special Issue constitutes 12 papers among which 10 are articles and the remainder two are technical notes. Most of the published articles are of interest for the practice applications because research focus of these articles has been directed towards interpreting and predicting the mechanical behavior of unsaturated soils using various approaches. The remainder of the articles, highlight instrumentation and new equipment that can be used for measuring suction.

A succinct summary of the technical papers and technical notes is provided in the following.

Sai K. Vanapalli

Sai.Vanapalli@uottawa.ca

1 Department of Civil Engineering, University of Ottawa, Ottawa, Canada

2 Department of Civil Engineering, University of Texas at Arlington, Arlington, TX, USA
The technical article titled, "Water Permeability Function for Soils that Undergo Volume Change as Suction Changes" authored by Zhang et al. [1] focuses on both volume change and desaturation behavior of soils when soil suction is increased. A laboratory data set for Regina clay, which is a typical expansive clay from Canada, is presented and interpreted. A procedure that can be used for the estimation of the saturated/unsaturated coefficient of permeability function for a soil that undergoes volume change and desaturation as soil suction increases is proposed.

The technical article titled, "Use of Dual Capillary Barrier as Cover System for a Sanitary Landfill in Singapore" authored by Rahardjo et al. [2] investigates the performance of a dual capillary barrier in Singapore in minimizing rainwater infiltration into a sanitary landfill. The SWCC and permeability function were used in the finite element seepage analyses to study the effect of climate change on the soil cover system. The results from the seepage analyses show that the dual capillary barrier was effective in minimizing rainwater infiltration into the sanitary landfill.

The technical article titled, "Swelling and Collapse of Unsaturated Soils due to Inundation Under One-Dimensional Loading" authored by Wijaya and Leong [3] discusses the wetting-induced volume change and net normal stress change of unsaturated soil by using swell and constant volume tests. A method to determine the swelling and collapse settlement due to different net normal stresses has been proposed. The proposed method is useful in providing the upper bound estimation of the swelling and collapse.

The technical article titled, "Soil Suction Measurement of Unsaturated soils with a Sensor using Fixed-matrix Porous Ceramic Discs" authored by Tripathy et al. [4] 
presents suction measurements in case of unsaturated soils using a commercially available water potential sensor. The sensor uses ceramic discs of predetermined pore-size distribution for suction measurement and a surface mounted thermistor to take temperature readings. The test results clearly showed that under predetermined conditions, the water potential sensor can be used to measure soil suction greater than $1500 \mathrm{kPa}$, within a few hours.

The technical article titled, "Modelling the Mechanical Properties of a Compacted Glacial Till" authored by Vanapalli and Han [5] uses a unified model, with a one constant model parameter that does not need to be calibrated to predict the variation of the several mechanical properties such as the shear strength, unconfined compression strength, undrained elastic modulus, and resilient modulus with respect to suction for a compacted glacial till. The mechanical properties were further used in numerical studies to model the load settlement behavior of model footing tests performed on the same soil. The study shows a good agreement between the measured and modelled load-settlement behavior and the bearing capacity at various suction levels.

The technical article titled, "Procedure to Estimate the Seismic Settlement of Partially Saturated Soils" authored by Ghayoomi and McCartney [6] introduces a step-by-step procedure to estimate the seismic settlement of a soil layer with a given initial relative density and degree of saturation. This methodology was followed to estimate the seismic settlement of different sand layers having different initial relative densities.

The technical article titled, "Useful Effect of PoreWater Surface Tension on Tensile Strength of Unsaturated Sand" authored by Jindal et al. [7] investigates the tensile behaviour of unsaturated sand both experimentally and theoretically. A custom-built direct tension apparatus was employed to perform direct tension tests on unsaturated sand specimens at different saturations levels and packing dry densities.

The technical article titled, "Influence of Mineral Montmorillonite on Soil Suction Modeling Parameters of Natural Expansive Clays" authored by Pedarla et al. [8] reports that the air entry values and the residual moisture contents determined from SWCC are independent of the degree of expansiveness of a soil. From the analysis of SWCC modeling parameters, it is observed that the air entry value is strongly related with the percentage of mineral montmorillonite. Pore size distribution and gradation parameters did not exhibit any variation with change in clay fraction or percent mineral montmorillonite.

The technical article titled, "Mechanical Behaviour of a Compacted Residual Soil of Gneiss from Brazil under Constant Water Content Condition" authored by de Oliveira et al. [9] reports results from tests performed on compacted soil specimens of a residual gneiss from Brazil using a conventional triaxial testing equipment, under constant water content condition, to study the influence of soil structure on the matric suction development in the soil specimens during testing. The results suggest that the changes in matric suction under constant water content condition depend mainly on the volume change behavior of the test soil, which, in turn, is influenced by the level of confining pressure, the degree of saturation, and the soil structure.

The technical article titled, "Incorporating temperature Effects in Soil-water Characteristic Curves" authored by Roshani and Infante Sedano [10] presents a rational approach to describe the effect of temperature on the SWCC of an unsaturated soil under isothermal conditions. A simple equation based on the relationship between temperature and the capillary rise is applied to find the air entry value at different temperatures when its value is known at a reference temperature. The comparison between experimental results as well as published SWCC data from the literature using the proposed equation indicate that the proposed method has great potential to successfully predict the measured SWCC with respect to temperature.

The technical note titled, "Effect of Fertilizers and Fly Ash Addition on Suction-Water Content Relationship of a Sandy Soil" authored by Malaya and Sreedeep [11] evaluates the tensiometer measurements in locally available, non-plastic sandy soil mixed with fertilizer or fly ash by using two different suction measurement procedures. The study indicated that these additives, in the form of solid inclusions, would alter the water retention measurement using tensiometer.

The technical note titled, "Determination of Swelling Characteristics Using Soil Water Characteristic Curve Parameter" authored by Rao [12] deals with the determination of swell potential and swell pressure from one of the slope parameters of the SWCC. Successful comparisons were reported between the estimated swelling parameters, swell potential and swell pressure computed from the SWCC with the measured values from the series of swelling experiments.

We appreciate the Indian Geotechnical Journal of Springer Nature Publications for inviting us as Guest Editors for this Special Issue. We are also confident that this issue would encourage more authors to publish their research in the area of unsaturated soils in this journal in the near future.

Acknowledgments We are extremely thankful to the reviewers for giving their time and providing comments and critique that have been valuable in bringing out this issue, particularly to members of the Unsaturated Soils Committee of the Geo-Institute of the ASCE, Members of the Canadian Geotechnical Society and several others 
whose research interests are in the area of unsaturated soils. We are thankful to the authors for extending their fullest cooperation in preparing the manuscripts as per the guidelines of the journal, taking into account the reviewers' comments and revising them in a prompt manner. Special thanks go to Dr. Zhong Han for his help on many fronts with this Special Issue. We acknowledge the Indian Geotechnical Journal for approving publication of the summarized papers above in this Special Issue. Last but not the least, we thank the Editor-in-Chief, Dr. G. L. Sivakumar Babu and the production team of Indian Geotechnical Journal for their continuous support and encouragement.

\section{References}

1. Zhang F, Fredlund DG, Wilson GW (2016) Water permeability function for soils that undergo volume change as suction changes. Indian Geotech J. doi:10.1007/s40098-016-0187-5

2. Rahardjo H, Satyanaga A, Harnas FR, Leong EC (2016) Use of dual capillary barrier as cover system for a sanitary landfill in Singapore. Indian Geotech J. doi:10.1007/s40098-015-0173-3

3. Wijaya M, Leong EC (2016) Swelling and collapse of unsaturated soils due to inundation under onedimensional loading. Indian Geotech J. doi:10.1007/s40098-015-0172-4

4. Tripathy S, Al-Khyat S, Cleall PJ, Baille W, Schanz T (2016) Soil suction measurement of unsaturated soils with a sensor using fixed-matrix porous ceramic discs. Indian Geotech J. doi: 10.1007/s40098-016-0200-z
5. Vanapalli SK, Han Z (2016) Modelling the mechanical properties of a compacted glacial till. Indian Geotech J. doi: 10.1007/s40098-016-0183-9

6. Ghayoomi M, McCartney JS (2016) Procedure to estimate the seismic settlement of partially saturated soils. Indian Geotech J. doi:10.1007/s40098-015-0176-0

7. Jindal P, Sharma J, Bashir R (2016) Useful effect of pore-water surface tension on tensile strength of unsaturated sand. Indian Geotech J. doi:10.1007/s40098-016-0184-8

8. Pedarla A, Acharya R, Bheemasetti T, Puppala AJ, Hoyos LR (2016) Influence of mineral montmorillonite on soil suction modeling parameters of natural expansive clays. Indian Geotech J. doi:10.1007/s40098-015-01751

9. de Oliveira OM, Li P, Marinho FAM, Vanapalli SK (2016) Mechanical behaviour of a compacted residual soil of gneiss from Brazil under constant water content condition. Indian Geotech J. doi:10.1007/s40098-016-0190-x

10. Roshani P, Infante Sedano JÁ (2016) Incorporating temperature effects in soil-water characteristic curves. Indian Geotech J. doi: 10.1007/s40098-016-0201-y

11. Malaya C, Sreedeep S (2016) Effect of fertilizers and fly ash addition on suction-water content relationship of a sandy soil. Indian Geotech J. doi:10.1007/s40098-015-0174-2

12. Rao BH (2016) Determination of swelling characteristics using soil water characteristic curve parameter. Indian Geotech J. doi: 10.1007/s40098-016-0199-1 